\title{
PROJETOS DE LEI RELACIONADOS A BANHEIROS PÚBLICOS EM BELO HORIZONTE: UMA ANÁLISE COM ÊNFASE NOS DIREITOS HUMANOS
}

\section{LAW PROJECTS RELATED TO PUBLIC TOILETS IN BELO HORIZONTE: AN ANALYSIS WITH EMPHASIS ON HUMAN RIGHTS}

\author{
Fernanda Deister Moreira ${ }^{(1)}$ \\ Doutoranda e Mestra em Saneamento, Meio Ambiente e Recursos Hídricos (SMARH/UFMG). Engenheira Ambiental e \\ Sanitarista (UFJF). Pesquisadora na linha de políticas públicas e gestão do saneamento.
}

Paula Rafaela Silva Fonseca ${ }^{(2)}$

Doutoranda e Mestra em Saneamento, Meio Ambiente e Recursos Hídricos (SMARH/UFMG). Engenheira Ambiental e Sanitarista (UFJF). Pesquisadora na linha de políticas públicas e gestão do saneamento.

Prisicila Soraia da Conceição Ribeiro ${ }^{(3)}$

Doutoranda em Saneamento, Meio Ambiente e Recursos Hídricos (SMARH/UFMG). Mestre em Engenharia Civil e Engenheira Ambiental (UFV). Pesquisadora na linha de políticas públicas e gestão do saneamento.

Ricardo de Sousa Moretti ${ }^{(4)}$

Engenheiro Civil, Mestre em Engenharia de Solos e Doutor em Engenharia de Construção Civil e Urbana pela Escola Politécnica da USP. Professor do Programa de Planejamento e Gestão do Território da UFABC.

E-mail ${ }^{(1)}: \underline{\text { fernandadeister@ufmg.br }}$

\section{RESUMO}

O objetivo do presente trabalho é apresentar os Projetos de Lei (PL) relacionados a banheiros públicos no município de Belo Horizonte e discuti-los à luz dos conteúdos normativos dos direitos humanos à água e ao esgotamento sanitário (DHAS). Para isso, os PLs foram foram acessados no website da Câmara de Vereadores do município e avaliados segundo análise de conteúdo temática categorial, utilizando-se como categorias os elementos normativos dos DHAS em esferas da vida além do domicílio. Foram encontrados 12 PLs, sendo que dois PLs foram excluídos por não ter seus documentos disponíveis. Das PLs analisadas, 6 foram arquivadas e 4 foram rejeitadas. O elemento disponibilidade foi o mais representado nos documentos, seguido de qualidade e segurança. O elemento menos identificado, por sua vez, foi privacidade, aceitabilidade e dignidade. Os resultados demonstram pouca prioridade dada à questão nessa esfera de poder, descaso reforçado pelo vazio normativo nos âmbitos federal e estadual.

\begin{abstract}
This paper aims to present the Law Projects (LP) related to public toilets in the city of Belo Horizonte and discuss them in light of the normative contents of the human rights to water and sanitation (DHAS). For this, the LPs were accessed on the website of the City Council of the city and evaluated according to categorical thematic content analysis, using the normative elements of the DHAS in spheres of life beyond the home as categories. 12 PLs were found, and two PLs were excluded for not having their documents available. Of the PLs analyzed, 6 were archived and 4 were rejected. The availability element was the most represented in the documents, followed by quality and security. The least identified element, in turn, was privacy, acceptability and dignity. The results show little priority given to the issue in this sphere of power, a neglect reinforced by the regulatory vacuum at the federal and state levels.
\end{abstract}

Palavras-chave: 1. Espaços Públicos 2. Cidades 3. Saneamento 4. Saúde Pública 


\section{INTRODUÇÃO}

Banheiros públicos são equipamentos urbanos essenciais que contribuem para que a população tenha conforto em circular em espaços públicos e usufrua do seu direito ao saneamento em esferas da vida além do domicílio (HELLER, 2019; MOREIRA, REZENDE, PASSOS, 2021). Um relatório recente da ONU (A / HRC / 42/47), com foco em acesso à água e ao esgotamento sanitário em espaços públicos, traz a interface do direito de acesso a banheiros públicos em relação às populações que possuem esse direito negligenciado (mulheres e meninas, trabalhadores de rua, cidadãos em situação de rua, idosos, pessoas com deficiência e pessoas transgêneros) (HELLER, 2019). Existem diferentes usuários de banheiros em espaços públicos e essa diversidade e vulnerabilidades devem ser levadas em consideração na tomada de decisões e no desenvolvimento de políticas públicas que atendam a todas as necessidades, uma vez que, o saneamento, para além da abordagem tecnológica, encontra-se na esfera da política pública, área de atuação do Estado (HELLER; CASTRO, 2007).

No Brasil, apesar da diretriz internacional, não existem políticas públicas a nível nacional que tornem compulsória a provisão desse equipamento urbano. Desde a redemocratização, a temática dos banheiros públicos não aparece em legislação federal até o ano de 2000, com a Lei da Acessibilidade, que estabelece que os banheiros de uso público em parques, praças, jardins e espaços livres públicos devem ser acessíveis e dispor, pelo menos, de um sanitário e um lavatório que atendam às especificações das normas técnicas da ABNT relacionada a infraestruturas adaptadas para deficientes físicos (BRASIL, 2000). Em 2019, foi aprovada a Lei Federal $n^{\circ} 13.825 / 2019$ que altera a Lei de Acessibilidade ao adicionar a obrigatoriedade de que, em todo evento público ou privado, $10 \%$ dos banheiros químicos disponíveis sejam destinados a pessoas com deficiência física ou dificuldade motora (BRASIL, 2019).

Em 2018, foi aprovada a Lei Federal $n^{\circ}$ 13.647/2018, que estabeleceu a obrigatoriedade de equipamentos para evitar o desperdício de água em banheiros destinados ao público (BRASIL, 2018a). Também em 2018, a Lei Federal no 13.724/2018, que institui o Programa Bicicleta Brasil, dispõe sobre a responsabilidade de órgãos governamentais e não governamentais na instalação de banheiros públicos, em locais estratégicos, com a finalidade de fomentar o Programa (BRASIL, 2018b). A mais recente Lei Federal que abarca o assunto é a Lei $n^{\circ} 14.029 / 2020$, que dispõe sobre a transposição e a reprogramação de saldos financeiros constantes dos fundos de assistência social dos estados, do Distrito Federal e dos municípios, provenientes de repasses federais. Em seu texto, há a menção sobre a disponibilização de água potável e acesso a banheiros públicos para atendimento à população em situação de rua (BRASIL, 2020).

Apesar de diversas legislações abordarem a questão dos banheiros públicos de forma tangente, como afirmado anteriormente, não existe um marco nacional legal sobre a provisão de banheiros públicos; mediante o vazio normativo no âmbito federal, essa responsabilidade recai aos estados e, principalmente, aos municípios, titulares dos serviços públicos de saneamento básico, que possuem responsabilidade indelegável quanto ao planejamento da gestão. E, neste cenário, entendeu-se que a esfera para a busca de respostas sobre a entrada do tema na agenda das políticas públicas seriam os municípios. Desta forma, escolheu-se o município de Belo Horizonte para o estudo, tendo como objetivo apresentar os projetos de lei de banheiros públicos no município, discutidos à luz dos conteúdos normativos dos DHAS.

\section{METODOLOGIA}

A fim de alcançar os objetivos deste trabalho, os projetos de Lei foram acessados no website da Câmara de Vereadores de Belo Horizonte, através de ferramenta de busca, adotando-se o filtro "Banheiros Públicos", em julho de 2021. Para a análise dos PLs municipais, lançou-se mão de uma 
análise de conteúdo (AC) temática categorial, que consiste em descobrir temas ou "núcleos de sentido" a fim de compreender o que a repetição desses temas ou a presença/falta destes representa para o objetivo escolhido (BARDIN, 1977). As categorias definidas para busca nos documentos foram os elementos normativos dos DHAS em esferas da vida além do domicílio: disponibilidade, acessibilidade física, acessibilidade financeira, privacidade e dignidade e qualidade e segurança. A análise de conteúdo de todos os PLs municipais passaram pelo crivo das três pesquisadoras a fim de assegurar uma análise robusta.

Ao todo, 12 Projetos de Lei relacionados a banheiros públicos foram encontrados na plataforma de busca da Câmara de Vereadores de Belo Horizonte, desde 2005. Dois PLs não tinham seus documentos disponíveis (PL 258/2005 e PL 476/2005) e foram excluídos da análise.

Por fim, vale destacar que a complexidade em torno da tramitação dos Projetos de Lei não foi o objetivo de discussão deste trabalho. O status das PLs serão citadas, mas abordar com profundidade questões partidárias e administrativas não cabem dentro do escopo deste artigo.

\section{RESULTADOS E DISCUSSÃO}

O ano com mais projetos relacionados a banheiros públicos foi 2013. Atualmente, não há PLs sobre o assunto em tramitação, seis PLs foram arquivados e quatro foram rejeitados (sendo 3 vetados pelos prefeitos em exercício da época). A seguir, os Projetos de Lei são apresentados no Quadro 1.

Quadro 1 - Turno da realização das oficinas

\begin{tabular}{|c|c|c|c|c|c|}
\hline $\mathrm{N}^{\mathrm{o}}$ do PL & Ano & Autor & Descrição & $\begin{array}{l}\text { Elementos normativos do } \\
\text { DHAES contemplados }\end{array}$ & Status \\
\hline 683 & 2009 & Luís Tibé & $\begin{array}{l}\text { dispõe sobre a instalação de banheiros } \\
\text { públicos nas estações de metrô de Belo } \\
\text { Horizonte }\end{array}$ & $\begin{array}{l}\text { Disponibilidade; } \\
\text { Acessibilidade }\end{array}$ & Arquivado \\
\hline 755 & 2009 & Fred Costa & $\begin{array}{l}\text { dispõe sobre a proibição da cobrança } \\
\text { pelo uso de banheiros públicos em } \\
\text { edificações destinadas ao transporte } \\
\text { público ou privado }\end{array}$ & Acessibilidade financeira & $\begin{array}{l}\text { Vetado/ } \\
\text { Rejeitado }\end{array}$ \\
\hline 1278 & 2010 & Pablo César Pablito & $\begin{array}{l}\text { dispõe sobre a criação de área } \\
\text { destinada a instalação de banheiros } \\
\text { públicos permanentes nas praças e } \\
\text { parques municipais, próximo às } \\
\text { estações de metrô, ferroviárias e } \\
\text { terminais rodoviários e locais } \\
\text { próximos a pontos de relevante } \\
\text { interesse turístico }\end{array}$ & $\begin{array}{c}\text { Disponibilidade; Qualidade } \\
\text { e Segurança }\end{array}$ & Rejeitado \\
\hline 2218 & 2012 & Joel Moreira Filho & $\begin{array}{l}\text { Estabelece condições de higiene em } \\
\text { banheiros públicos. }\end{array}$ & $\begin{array}{c}\text { Disponibilidade; Qualidade } \\
\text { e Segurança; } \\
\text { Aceitabilidade, Privacidade } \\
\text { e Dignidade }\end{array}$ & Arquivado \\
\hline 299 & 2013 & Joel Moreira Filho & $\begin{array}{l}\text { Estabelece condições de higiene em } \\
\text { banheiros públicos. }\end{array}$ & $\begin{array}{c}\text { Disponibilidade; Qualidade } \\
\text { e Segurança; } \\
\text { Aceitabilidade, Privacidade } \\
\text { e Dignidade }\end{array}$ & Arquivado \\
\hline 341 & 2013 & Pablo César Pablito & $\begin{array}{l}\text { dispõe sobre a criação de área } \\
\text { destinada a instalação de banheiros } \\
\text { públicos permanentes nas praças e } \\
\text { parques municipais, próximo às }\end{array}$ & $\begin{array}{c}\text { Disponibilidade; Qualidade } \\
\text { e Segurança }\end{array}$ & Arquivado \\
\hline
\end{tabular}




\begin{tabular}{|c|c|c|c|c|c|}
\hline & & & $\begin{array}{c}\text { estações de metrô, ferroviárias e } \\
\text { terminais rodoviários e locais } \\
\text { próximos a pontos de relevante } \\
\text { interesse turístico }\end{array}$ & & \\
\hline 718 & 2013 & $\begin{array}{l}\text { Delegado Edson } \\
\text { Moreira }\end{array}$ & $\begin{array}{c}\text { dispõe sobre a instalação e } \\
\text { conservação dos banheiros públicos do } \\
\text { Município }\end{array}$ & $\begin{array}{c}\text { Disponibilidade; } \\
\text { Acessibilidade; } \\
\text { Acessibilidade } \\
\text { financeira;Qualidade e } \\
\text { Segurança. }\end{array}$ & $\begin{array}{l}\text { Vetado/ } \\
\text { Rejeitado }\end{array}$ \\
\hline 1854 & 2016 & Sérgio Tavares & $\begin{array}{c}\text { dispõe sobre a instalação e } \\
\text { conservação de banheiros públicos no } \\
\text { município }\end{array}$ & $\begin{array}{c}\text { Disponibilidade; Qualidade } \\
\text { e Segurança. }\end{array}$ & Arquivado \\
\hline 1932 & 2016 & $\begin{array}{c}\text { Professor Wendel } \\
\text { Mesquita }\end{array}$ & $\begin{array}{l}\text { dispõe sobre a instalação, conservação } \\
\text { e manutenção de banheiros públicos na } \\
\text { orla da Lagoa da Pampulha }\end{array}$ & $\begin{array}{c}\text { Disponibilidade; } \\
\text { Acessibilidade financeira }\end{array}$ & $\begin{array}{l}\text { Vetado/ } \\
\text { Rejeitado }\end{array}$ \\
\hline 161 & 2017 & Elvis Côrtes & $\begin{array}{c}\text { dispõe sobre a instalação de banheiros } \\
\text { públicos nas estações de metrô de Belo } \\
\text { Horizonte }\end{array}$ & $\begin{array}{l}\text { Disponibilidade, } \\
\text { Acessibilidade }\end{array}$ & $\begin{array}{l}\text { Arquiva- } \\
\text { do }\end{array}$ \\
\hline
\end{tabular}

Fonte: Adaptado da Câmara de Vereadores de Belo Horizonte

O fato de apenas 12 PLs municipais existirem sobre a temática em um horizonte de mais de 15 anos (2005-2021) demonstra pouca prioridade dada à questão nessa esfera de poder uma vez que nesse período foram 7809 PLs protocolados. Ao analisar os PLs, identificou-se que o elemento disponibilidade é o mais representado nos Projetos de Lei. Isso acontece porque para que os outros elementos sejam de fato contemplados, é necessário, primeiramente, que haja banheiros disponíveis.

Em Belo Horizonte, a questão dos banheiros não é priorizada por falta de um responsável principal por esses serviços, de acordo com um gestor da prefeitura a questão dos banheiros ficou "sem pai, nem mãe", além de apontar a falta de prioridade do assunto no executivo e no legislativo (MOREIRA, 2021). No caso dos PLs analisados, quatro foram rejeitados. Três deles chegaram a se tornar Proposições de Lei e foram vetados pelo executivo sob a prerrogativa de inconstitucionalidade, ou seja, de que o legislativo estaria se debruçando sobre uma questão administrativa, que cabe apenas ao executivo. Além disso, os vetos trazem como justificativa o fato de no Código de Posturas do município já prever a instalação de sanitários públicos. Moreira (2021) argumenta que a não obrigatoriedade da oferta de banheiros públicos ou a falta de uma diretriz que oriente o executivo a ofertar o serviço, torna a disponibilidade de banheiros refém do governo em exercício, que pode tomála como prioritária ou não.

O segundo elemento mais citado é o de qualidade e segurança. Nos PLs, o tema vem marcado por questões de higiene, conservação e manutenção dos banheiros para garantir condições mínimas de uso. A conservação e manutenção de banheiros públicos foi citado como o principal desafio do poder público atinente à provisão dos banheiros em recente pesquisa realizada em Belo Horizonte (MOREIRA, 2021). Ademais, já foi comprovado a possibilidade de contaminação em banheiros públicos, trazendo prejuízos à saúde dos usuários (YEON et al., 2001; NIGATU et al., 2001). Apesar de as justificativas dos Projetos de Lei não trazerem referências técnicas ou teóricas quanto a este elemento, percebe-se que questões de qualidade e segurança são senso comum quando relacionadas a banheiros públicos.

Além disso, há atenção à questão de gênero no PL 2218/2012 que traz peculiaridades para o banheiro feminino que deve ter utilidades especiais, buscando atender às demandas e necessidades desse público específico. Na literatura, a necessidade de considerar as demandas específicas do público feminino já é consolidada, uma vez que mulheres além de precisarem de urinar com mais frequência, 
podem desenvolver doenças na falta de banheiros ou por não usarem banheiros devido à suas condições de higiene, como sintomas do trato urinário inferior (YANG et al., 2010; Xu et al., 2018).

Apenas um quarto dos Projetos de Lei sobre banheiros públicos em Belo Horizonte abordaram questões relacionadas à acessibilidade financeira. Em seu texto ou justificativa, dois PLs traziam a gratuidade para deficientes físicos, idosos, estudantes e o outro trazia a gratuidade total de banheiros públicos em edificações do sistema de transporte urbano. Proibir a cobrança por banheiros públicos garante o acesso de pessoas em vulnerabilidade econômica e, dessa forma, esse público não seria negligenciado no caso da cobrança do serviço (HELLER, 2019).

A acessibilidade física também só aparece em três PLs que citam a obrigatoriedade de seguir as regras de acessibilidade da ABNT para adaptação dos banheiros para deficientes físicos. Apesar de a acessibilidade aparecer relacionada ao design do banheiro para acesso de pessoas com deficiência, não é discutido em nenhum desses PLs sobre o acesso contínuo do banheiro que garantiria que pessoas que contam apenas com essa alternativa, pudessem acessar durante a noite.

O elemento menos identificado nos textos e justificativas foi privacidade, aceitabilidade e dignidade, aparecendo em apenas dois Projetos de Lei que possuem o mesmo texto. Nesse caso, a identificação desse elemento se deu por meio da justificativa pela qual banheiros públicos devem ser instalados na cidade para evitar situações de constrangimento, principalmente para mulheres e na disposição sobre equipamentos específicos para os banheiros femininos. Como as necessidades biológicas das mulheres em relação aos banheiros são diferentes dos homens, especialmente durante a gravidez e menstruação (ANDREWS, 1990; GREED, 2016), é essencial para a realização dos direitos humanos, que essas particularidades sejam contempladas.

Cabe destacar que além dos conteúdos normativos dos direitos humanos à água e ao saneamento, devem ser assegurados os princípios de não discriminação e igualdade, acesso à informação, participação e prestação de contas. (HELLER, 2015). O PL com mais elementos contemplados é o PL 718/2013 que traz uma extensa justificativa passando por parágrafos da constituição federal que dispõe sobre o direito à saúde e à vida.

\section{CONCLUSÕES}

Apesar de os direitos à água e ao saneamento não serem explicitamente relacionados aos Projetos de Lei analisados, percebeu-se que seus elementos normativos quanto à provisão dos serviços em espaços públicos foram contemplados parcialmente no texto ou nas justificativas dos PLs. O elemento disponibilidade não se mostrou prioritário na agenda do legislativo pelo fato de não existir uma política pública materializada em lei, regulação ou outro instrumento normativo que torna compulsória a provisão desse direito. Portanto, a análise foi limitada à ótica dos direitos humanos em vista de compreender como os seus elementos são priorizados e justificados na agenda legislativa de Belo Horizonte, mostrando que, apesar do reconhecimento da importância dessa temática, pouca prioridade é dada ao assunto.

\section{REFERÊNCIAS}

ANDREWS, M. W. Sanitary conveniences and the retreat of the frontier: Vancouver, 1886-1926. BC Studies: The British Columbian Quarterly, n. 87, p. 3-22, 1990.

BELO HORIZONTE. Resolução Nº1480 de 07 de dezembro de 1990: dispõe sobre o regimento interno da câmara municipal de Belo Horizonte. Belo Horizonte, 1990. 
BRASIL. Lei $n^{\circ}$ 14.029, de 28 de julho de 2020: Dispõe sobre a transposição e a reprogramação de saldos financeiros constantes dos fundos de assistência social dos Estados, do Distrito Federal e dos Municípios, provenientes de repasses federais. Diário Oficial da União, Brasília, DF, 2020.

BRASIL. Lei $n^{\circ}$ 10.098, de 19 de dezembro de 2000: Estabelece normas gerais e critérios básicos para a promoção da acessibilidade das pessoas portadoras de deficiência ou com mobilidade reduzida, e dá outras providências. Diário Oficial da União, Brasília, DF, 2000.

BRASIL. Lei $\mathrm{n}^{\circ}$ 13.285, de 13 de maio de 2019: Altera a Lei no 10.098, de 19 de dezembro de 2000 (Lei de Acessibilidade), para estabelecer a obrigatoriedade de disponibilização, em eventos públicos e privados, de banheiros químicos acessíveis a pessoas com deficiência ou com mobilidade reduzida. Diário Oficial da União, Brasília, DF, 2019.

BRASIL. Lei $n^{\circ}$ 13.457, de 9 de abril de 2018: Estabelece a obrigatoriedade da instalação de equipamentos para evitar o desperdício de água em banheiros destinados ao público. Diário Oficial da União, Brasília, DF, $2018^{\mathrm{a}}$

BRASIL. Lei $\mathbf{n}^{\mathbf{0}}$ 13.724, de 4 de outubro de 2018: Institui o Programa Bicicleta Brasil (PBB) para incentivar o uso da bicicleta visando à melhoria das condições de mobilidade urbana. Diário Oficial da União, Brasília, DF, $2018 b$.

BARDIN, L. Análise de conteúdo. Lisboa: Edições 70, 225 p., 1977.

CÂMARA MUNICIPAL DE BELO HORIZONTE. Projeto de Lei no 683/2009: "Dispõe sobre a instalação de banheiros públicos nas estações de metrô de Belo Horizonte”. 2009.

CÂMARA MUNICIPAL DE BELO HORIZONTE. Projeto de Lei no 755/2009: "Dispõe sobre a proibição de cobrança pelo uso de banheiros públicos instalados em edificações destinadas ao sistema de transporte público ou privado do município". 2009.

CÂMARA MUNICIPAL DE BELO HORIZONTE. Projeto de Lei n 1278/2010. "Cria área destinada a instalação de banheiros públicos permanentes na forma que menciona." 2010.

CÂMARA MUNICIPAL DE BELO HORIZONTE. Projeto de Lei no 2218/2012: "Estabelece condições de higiene em banheiros públicos". 2012.

CÂMARA MUNICIPAL DE BELO HORIZONTE. Projeto de Lei n 341/2013: "Cria área destinada a instalação de banheiros públicos permanentes na forma que menciona.” 2013

CÂMARA MUNICIPAL DE BELO HORIZONTE. Projeto de Lei no 718/2013: "Dispõe sobre a instalação e conservação de banheiros públicos no Município e dá outras providências". 2013.

CÂMARA MUNICIPAL DE BELO HORIZONTE. Projeto de Lei n 1854/2016: “Dispõe sobre a instalação e conservação de banheiros públicos no município.” 2016

CÂMARA MUNICIPAL DE BELO HORIZONTE. Projeto de Lei nº 1932/2016: "Dispõe sobre a instalação, conservação e manutenção de banheiros públicos na orla da Lagoa da Pampulha”. 2016.

CÂMARA MUNICIPAL DE BELO HORIZONTE. Projeto de Lei no 161/2017: "Dispõe sobre a instalação de banheiros públicos nas estações de metrô em Belo Horizonte”. 2017.

CÂMARA MUNICIPAL DE BELO HORIZONTE. Projeto de Lei no 199/2017: "Estabelece condições de higiene em banheiros públicos”. 2017.

GREED, C. Taking women's bodily functions into account in urban planning and policy: public toilets and menstruation. Town Planning Review, v. 87, n. 5, p. 505-524, 2016.

HELlER, L.; CASTRO, J. E. Política pública de saneamento: apontamentos teórico- conceituais. Engenharia Sanitaria e Ambiental, v. 12, n. 3, p. 284-295, 2007.

HELLER, L.. Human Rights to water and sanitation in spheres of life beyond the household with an emphasis on public spaces. Human Rights Council, UN. 2019.

HELLER, L. UNGA. United Nations General Assembly. Human Right to Water and Sanitation. Document A/RES/70/203. Geneva: UNGA, 2015. Disponível em: https://undocs.org/A/70/203. Acesso em : ago-2021.

MOREIRA, F.D.; REZENDE, S.; PASSOS, F. On-street toilets for sanitation access in urban public spaces: A systematic review. Utilities Policy, v. 70, p. 101186, 2021.

MOREIRA, F.D. Por uma política pública a partir do público da política: um estudo sobre banheiros na Orla da Lagoa da Pampulha sob a perspectiva dos direitos humanos. (Dissertação de Mestrado). Programa de Pós Graduação em Saneamento, Meio Ambiente e Recursos da Universidade Federal de Minas Gerais, 2021. 

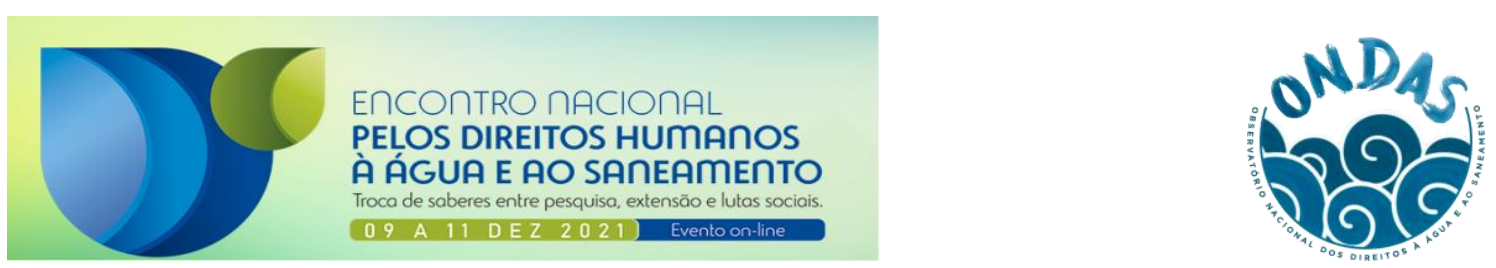

NEVES-SILVA, P.; HELLER, L. O direito humano à água e ao esgotamento sanitário como instrumento para promoção da saúde de populações vulneráveis. Ciência \& Saúde Coletiva, v. 21, p. 1861-1870, 2016.

NIGATU, W. et al. Comparative study on the level of bacteriological contamination of automatic teller machines, public toilets and public transport commercial motorcycle crash helmets in Kigali City, Rwanda. East African medical journal, v. 91 , n. 12, p. 467-476, 2014.

UN, UNITED NATIONS. The Global Initiative for Economic, Social and Cultural Rights. Human Rights-Based Approach to Water in Informal Settlements: A Guide for Practitioners. Geneva. 2015.

$\mathrm{XU}$, D. et al. Toileting behaviour and related health beliefs among Chinese female nurses. International journal of clinical practice, v. 70, n. 5, p. 416-423, 2016.

YEON, J.W.; CHANG, M. W.; KIM, K.H. Detection and isolation of genital Mycoplasmas from public toilet bowls. Journal of Bacteriology and Virology, v. 32, n. 3, p. 231-238, 2002.

YANG, K.N. et al. Female voiding postures and their effects on micturition. International urogynecology journal, v. 21, n. 11, p. 1371-1376, 2010. 